\title{
Incidence of infection of carabid beetles (Coleoptera: Carabidae) by laboulbenialean fungi in different habitats
}

\author{
SHINII SUGIURA ${ }^{1}$, KAZUO YAMAZAKI ${ }^{2}$ and HAYATO MASUYA ${ }^{1}$
}

\begin{abstract}
${ }^{1}$ Forestry and Forest Products Research Institute, 1 Matsunosato, Tsukuba, Ibaraki 305-8687, Japan; e-mail: ssugiura@affrc.go.jp
${ }^{2}$ Osaka City Institute of Public Health and Environmental Sciences, Osaka 543-0026, Japan
\end{abstract}

\begin{abstract}
Key words. Coleoptera, Carabidae, ectoparasitic fungi, Ascomycetes, Laboulbenia, microhabitat, overwintering sites
\end{abstract}
\begin{abstract}
The prevalence of obligate parasitic fungi may depend partly on the environmental conditions prevailing in the habitats of their hosts. Ectoparasitic fungi of the order Laboulbeniales (Ascomycetes) infect arthropods and form thalli on the host's body surface. Although several studies report the incidence of infection of certain host species by these fungi, quantitative data on laboulbenialean fungus-host arthropod interactions at the host assemblage level are rarely reported. To clarify the effects of host habitats on infection by ectoparasitic fungi, the incidence of infection by fungi of the genus Laboulbenia (Laboulbeniales) of overwintering carabid beetles (Coleoptera: Carabidae) in three habitats, a riverside (reeds and vines), a secondary forest and farmland (rice and vegetable fields), were compared in central Japan. Of the 531 adults of 53 carabid species (nine subfamilies) collected in the three habitats, a Laboulbenia infection of one, five and one species of the carabid subfamilies Pterostichinae, Harpalinae and Callistinae, respectively, was detected. Three species of fungus were identified: L. coneglanensis, L. pseudomasei and L. fasciculate. The incidence of infection by Laboulbenia was higher in the riverside habitat $(8.97 \%$ of individuals; $14 / 156)$ than in the forest $(0.93 \%$; $2 / 214)$ and farmland $(0 \% ; 0 / 161)$ habitats. Furthermore, the incidence of infection by Laboulbenia in the riverside habitat ranged from 0 to $33.3 \%$ and differed significantly in the ten microhabitats (riverbank, edge of track, tall reeds, kudzu vines, slope of a hollow, rotten wood, vine reeds, under stones, the shoulder of a terrace and marshy ground) where the carabid beetles overwintered. These results suggest that host habitats and microhabitats are closely associated with successful infection by laboulbenialean fungi.
\end{abstract}

\section{INTRODUCTION}

Fungi associated with arthropods are known to have various types of relationships with their hosts (e.g., pathogenic, parasitic, phoretic and mutualistic; Roy, 1994; Vega \& Blackwell, 2005; Roy \& Cottrell, 2008). Ectoparasitic fungi of the order Laboulbeniales are obligate ectoparasites that infect arthropods, mainly insects, and form thalli on the host's body surface (Tavares, 1985; Weir \& Hammond, 1997a, b). As laboulbenialean fungi are easy to detect on the integument of host arthropods (Weir \& Hammond, 1997a, b) there are several studies of the incidence of infection of certain hosts by these fungi (Welch et al., 2001; Zerm \& Adis, 2004; Riddick \& Schaefer, 2005; Harwood et al., 2006; Riddick, 2006). Quantitative data on laboulbenialean fungus-host arthropod interactions at the host assemblage level (multiple host species), however, are rarely reported.

The diversity of Laboulbeniales depends on the host arthropod taxa. For example, the insect order Coleoptera includes $80 \%$ of the known host arthropod species (Weir \& Hammond, 1997b). Furthermore, the coleopteran families, Carabidae and Staphylinidae, include 30\% and 27\% of coleopteran host species of Laboulbenialean fungi in Europe and $27 \%$ and $26 \%$ in Asia, respectively (Weir \& Hammond, 1997a, b). The diversity of laboulbeniales also depends on the host arthropod guilds and habitats (e.g., predators and forest litter; Weir \& Hammond, 1997b). Laboulbenialean fungi are likely to infect hosts that overwinter as adults and have overlapping generations of adults (Weir \& Hammond, 1997a, b). In these fungi, the adhesive ascospores are transmitted during direct contact between two host individuals, which often involves sexual encounters (Weir \& Hammond, 1997b). Indirect infection (substrate infection) is thought to be extremely unimportant compared to direct infection because spore survival is extremely short and not greatly affected by environmental conditions (De Kesel, 1996a, b; Weir \& Hammond, 1997b). However, the successful infection of hosts by laboulbenialean fungi is likely to depend on the conditions in the microhabitats occupied by the hosts (De Kesel, 1996b). Only a few studies explore the difference in the incidence of infection by laboulbenialean fungi among microhabitats (Andersen \& Skorping, 1991; De Kesel, 1996b). Andersen \& Skorping (1991) examined the incidence of infection in assemblages of the carabid genus Bembidion in different microhabitats along a riverbank and showed it is higher in vegetation than in open habitats. De Kesel (1996b) experimentally infected several carabid species living in different microhabitat conditions (i.e., in terms of soil composition) and showed that host microhabitats as well as host taxa are important for the successful establishment of these fungi.

Beetles of the family Carabidae, the most abundant host group for laboulbenialean fungi (Weir \& Hammond, 1997a, b), inhabit various types of environment (Lövei \& Sunderland, 1996). Therefore, carabid beetles have frequently been used as environmental indicators of urbanization and forest fragmentation (Niemelä et al., 2002; Rainio \& Niemelä, 2003). Habitats such as grasslands, 
Riverside

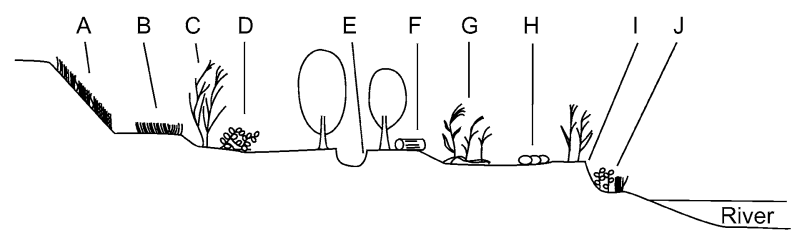

Forest

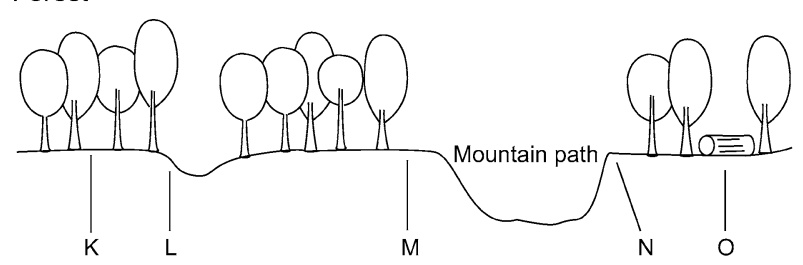

Farmland

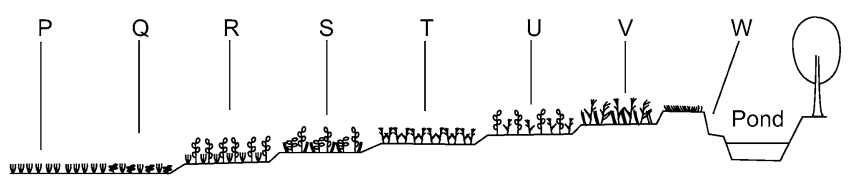

Fig. 1. Cross-sectional outline of the ten, five and eight microhabitats sampled at the riverside, forest and farmland sites, respectively. A - riverbank; $\mathrm{B}$ - border of path; $\mathrm{C}$ - tall reeds; D - kudzu vine; $\mathrm{E}$ - slope of a hollow; F - rotten wood; G vine reeds; $\mathrm{H}$ - stones; I - shoulder of a terrace; $\mathrm{J}$ - marshy ground (see Table 1 for details); $\mathrm{K}$ - forest floor; $\mathrm{L}$ - small hollow in the forest; $\mathrm{M}$ - forest edge; $\mathrm{N}$ - side of a mountain path; $\mathrm{O}$ - rotten wood; $\mathrm{P}$ - arable rice field; $\mathrm{Q}$ - wet fallow rice field; $\mathrm{R}$ - dry fallow rice field; $\mathrm{S}$ - fallow vegetable field $1 ; \mathrm{T}$ fallow potato field; $\mathrm{U}$ - fallow vegetable field 2; $\mathrm{V}$ - old fallow field; W - bank of an irrigation pond (see Yamazaki et al., 1999, 2002, 2003 for details).

forests and anthropogenic vegetation constitute the larger spatial features of environments, whereas microhabitats such as marshy ground, rotten wood and the undersides of stones constitute the smaller features of environments. The incidence of infection by laboulbenialean fungi may depend on the habitats and microhabitats in which the host carabids occur. However, the relationship between carabid assemblages and the ectoparasitic fungi has not been explored at spatial scales larger than microhabitats.

Here, we report differences in the incidence of infection by laboulbenialean fungi of overwintering carabid beetles (Coleoptera: Carabidae) in three habitats in central Japan: riverside, secondary forest and farmland habitats. Most laboulbenialean host species, such as carabids, overwinter as adults and have overlapping adult generations (Lövei \& Sunderland, 1996; Weir \& Hammond, 1997a, b; Yamazaki et al., 1999, 2002, 2003, 2004). Overwintering sites of carabid beetles occur within, or near, the habitats they occupy in summer (Yamazaki et al., 1999, 2002, 2003, 2004), which makes overwintering carabid beetles appropriate subjects for investigating the effects of habitats on the incidence of infection by laboulbenialean fungi.

\section{MATERIAL AND METHODS}

To quantify the effects of host habitat on infection by ectoparasitic fungi, the incidence of infection of adult carabids by laboulbenialean fungi was determined by systematically sampling three habitats, a riverside (Yamazaki et al., 1999), a secondary forest (Yamazaki et al., 2002) and farmland (Yamazaki et al., 2003). We focused on infection during winter, when many carabid beetles hibernate as adults underground and inside rotten wood, because the incidence of infection by laboulbenialean fungi is known to vary seasonally (Zerm \& Adis, 2004). Beetles were collected at a riverside site in the middle reaches of the Kizu River, Kyoto ( $34^{\circ} 53^{\prime} \mathrm{N}, 135^{\circ} 41^{\prime} \mathrm{E}$; ca. $10 \mathrm{~m}$ elev.) in Mar 1997, at a secondary forest site on the west-facing slope of Mt. Nukatayama, Osaka $\left(34^{\circ} 40^{\prime} \mathrm{N}, 135^{\circ} 41^{\prime} \mathrm{E}\right.$; $370-450 \mathrm{~m}$ elev.) in Dec 1998 and Mar 1999 and at a farmland site in a rural area of Son-enji, Osaka ( $34^{\circ} 48^{\prime} \mathrm{N}, 135^{\circ} 43^{\prime} \mathrm{E}$; ca. $100 \mathrm{~m}$ elev.) in Dec 1999, Mar 2000, and Mar 2001. The distance between sites (habitats) ranged from 8 to $24 \mathrm{~km}$. The riverside site comprised a mosaic of grassland and willow shrubs (Fig. 1.; Table 1; Yamazaki et al., 1999). The secondary forest was composed of evergreen and deciduous broad-leaved tree species such as

TABLE 1. Microhabitats at the riverside site on the middle reaches of the Kizu River, Kyoto.

\begin{tabular}{|c|c|c|}
\hline Code $^{1}$ & Microhabitat $^{1}$ & Description $^{2}$ \\
\hline A & Riverbank & $\begin{array}{l}\text { The waterside slope of the river bank. This habitat was at the farthest point on the slope above the river. } \\
\text { Lolium multiflorum grew on fine sand with humus. }\end{array}$ \\
\hline $\mathrm{B}$ & Edge of track & $\begin{array}{l}\text { A track running along the outer edge of the main terrace. Lolium multiflorum, Rosa multiflora, Rumex } \\
\text { acetosa and Lycoris radiata grew beside the track and the soil consisted of fine sand with humus. }\end{array}$ \\
\hline $\mathrm{C}$ & Tall reeds & $\begin{array}{l}\text { The outer edge of the main terrace was covered mainly by tall reeds (Phragmites karka) growing in fine } \\
\text { sand with rich humus. }\end{array}$ \\
\hline $\mathrm{D}$ & Kudzu vines & $\begin{array}{l}\text { The outer edge of the main terrace was covered mainly with kudzu (Pueraria lobata) growing in fine } \\
\text { sand with rich humus. }\end{array}$ \\
\hline $\mathrm{E}$ & Slope of a hollow & $\begin{array}{l}\text { A small hollow under willow trees (Salix spp.) in the middle of the main terrace. The soil consisted of } \\
\text { coarse sand with willow roots and little humus. }\end{array}$ \\
\hline $\mathrm{F}$ & Rotten wood & Rotten willow wood on the ground on the main terrace. \\
\hline $\mathrm{G}$ & Vine reeds & $\begin{array}{l}\text { Vine reeds (Phragmites japonica) growing along the inner edge of the main terrace. The soil consisted } \\
\text { of relatively dry coarse sand with little humus. }\end{array}$ \\
\hline $\mathrm{H}$ & Under stones & Fist- to rugby ball-sized stones on the ground of the main terrace. \\
\hline I & Shoulder of terrace & $\begin{array}{l}\text { A narrow terrace } 2-3 \mathrm{~m} \text { above the river. The soil chiefly consisted of wet hard clay. Phragmites com- } \\
\text { munis and Solidago altissima grew on this terrace. }\end{array}$ \\
\hline $\mathrm{J}$ & Marshy ground & $\begin{array}{l}\text { Along the edge of the narrow terrace, weeds such as Polygonum longisetum, Rorippa indica and grasses } \\
\text { grew on the marshy ground consisting of clay and fine sand. }\end{array}$ \\
\hline
\end{tabular}


TABLE 2. The number of carabid beetles collected at the three habitats (the number infected with Laboulbenia).

\begin{tabular}{|c|c|c|c|c|c|}
\hline \multirow{2}{*}{ Subfamily } & \multirow{2}{*}{ Species } & \multicolumn{3}{|c|}{ Habitat } & \multirow{2}{*}{ Total } \\
\hline & & Riverside & Forest & Farmland & \\
\hline \multirow[t]{3}{*}{ Carabinae } & Calosoma maximowiczi (Morawitz) & 0 & 1 & 0 & 1 \\
\hline & Damaster blaptoides Kollar & 16 & 0 & 0 & 16 \\
\hline & Ohomopterus yaconinus Bates & 4 & 21 & 1 & 26 \\
\hline \multirow[t]{3}{*}{ Scaritinae } & Clivina niponensis Bates & 0 & 0 & 1 & 1 \\
\hline & Dyschirius ordinatus Bates & 1 & 0 & 0 & 1 \\
\hline & Scarites terricola pacificus Bates & 0 & 0 & 3 & 3 \\
\hline Bembidiinae & Tachyura laetifica (Bates) & 1 & 0 & 0 & 1 \\
\hline \multirow[t]{11}{*}{ Pterostichinae } & Agonum chalcomus (Bates) & 2 & 0 & 8 & 10 \\
\hline & Colpodes japonicus (Motschulsky) & 0 & 0 & 1 & 1 \\
\hline & Lesticus magnus (Motschulsky) & 2 & 0 & 1 & 3 \\
\hline & Pterostichus haptoderoides japanensis Tschitscherine & 0 & 0 & 13 & 13 \\
\hline & Pterostichus latemarginatus (Straneo) & 0 & 90 & 0 & 90 \\
\hline & Pterostichus longinquus Bates & 0 & 0 & 25 & 25 \\
\hline & Pterostichus microcephalus (Motschulsky) & 6 & 0 & 2 & 8 \\
\hline & Pterostichus planicollis Motschulsky & $3(2)$ & 0 & 0 & $3(2)^{1}$ \\
\hline & Pterostichus sulcitarsis Morawitz & 1 & 0 & 2 & 3 \\
\hline & Pterostichus yoritomus Bates & 0 & 21 & 0 & 21 \\
\hline & Trigonotoma lewisii Bates & 0 & 20 & 0 & 20 \\
\hline \multirow[t]{5}{*}{ Zabrinae } & Amara chalcites DeJean & 35 & 0 & 13 & 48 \\
\hline & Amara congrua Morawitz & 0 & 0 & 18 & 18 \\
\hline & Amara gigantea Motschulsky & 1 & 0 & 0 & 1 \\
\hline & Amara macronota ovalipennis Solsky & 2 & 0 & 0 & 2 \\
\hline & Amara simplicidens Morawitz & 4 & 0 & 0 & 4 \\
\hline \multirow[t]{22}{*}{ Harpalinae } & Acupalpus inornatus Bates & 0 & 0 & 1 & 1 \\
\hline & Anisodactylus punctatipennis Morawitz & 0 & 0 & 1 & 1 \\
\hline & Anisodactylus sadoensis Schauberger & 13 & 0 & 0 & 13 \\
\hline & Anisodactylus signatus (Panzer) & 4 & 0 & 18 & 22 \\
\hline & Anoplogenius cyanescens (Hope) & 0 & 0 & 2 & 2 \\
\hline & Bradycellus grandiceps (Bates) & 0 & 0 & 6 & 6 \\
\hline & Bradycellus subditus (Lewis) & 2 & 0 & 13 & 15 \\
\hline & Harpalus capito Morawitz & 3 & 0 & 0 & 3 \\
\hline & Harpalus chalcentus Bates & 0 & 0 & 13 & 13 \\
\hline & Harpalus eous Tschitscherine & $8(6)$ & 0 & 0 & $8(6)^{1}$ \\
\hline & Harpalus griseus (Panzer) & $3(1)$ & 0 & 0 & $3(1)^{1}$ \\
\hline & Harpalus jureceki (Jedlicka) & 2 & 0 & 4 & 6 \\
\hline & Harpalus niigatanus Schauberger & $1(1)$ & 0 & 1 & $2(1)^{1}$ \\
\hline & Harpalus platynotus Bates & 4 & 0 & 0 & 4 \\
\hline & Harpalus sinicus Hope & $3(2)$ & 0 & 2 & $5(2)^{1}$ \\
\hline & Harpalus tinctulus Bates & 1 & 0 & 0 & 1 \\
\hline & Harpalus tridens Morawitz & 4 & 0 & 0 & 4 \\
\hline & Oxycentrus argutoroides (Bates) & 11 & $6(2)$ & 3 & $20(2)^{2}$ \\
\hline & Stenolophus fulvicornis Bates & 0 & 0 & 1 & 1 \\
\hline & Stenolophus iridicolor Redtenbacher & 0 & 0 & 5 & 5 \\
\hline & Trichotichnus congruus (Motschulsky) & 0 & 1 & 1 & 2 \\
\hline & Trichotichnus noctuabundus Habu & 0 & 0 & 1 & 1 \\
\hline Licininae & Diplocheila zeelandica (Redtenbacher) & 0 & 1 & 0 & 1 \\
\hline \multirow[t]{6}{*}{ Callistinae } & Chlaenius inops Chaudoir & $3(2)$ & 0 & 0 & $3(2)^{3}$ \\
\hline & Chlaenius kurosawai Kasahara & 7 & 0 & 0 & 7 \\
\hline & Chlaenius naeviger Morawitz & 0 & 26 & 1 & 27 \\
\hline & Chlaenius pallipes Gebler & 8 & 0 & 0 & 8 \\
\hline & Chlaenius posticalis Motschulsky & 1 & 0 & 0 & 1 \\
\hline & Haplochlaenius costiger (Chaudoir) & 1 & 25 & 0 & 26 \\
\hline \multirow[t]{4}{*}{ Lebiinae } & Lebidia octoguttata Morawitz & 0 & 2 & 0 & 2 \\
\hline & Total no. individuals (no. infected individuals) & $156(14)$ & $214(2)$ & $161(0)$ & $531(16)$ \\
\hline & No. species & 31 & 11 & 28 & 53 \\
\hline & No. infected species & 6 & 1 & 0 & 7 \\
\hline
\end{tabular}

Fungal species: ${ }^{1}$ Laboulbenia coneglanensis, ${ }^{2}$ L. pseudomasei, ${ }^{3}$ L. fasciculata (see Table 3). 


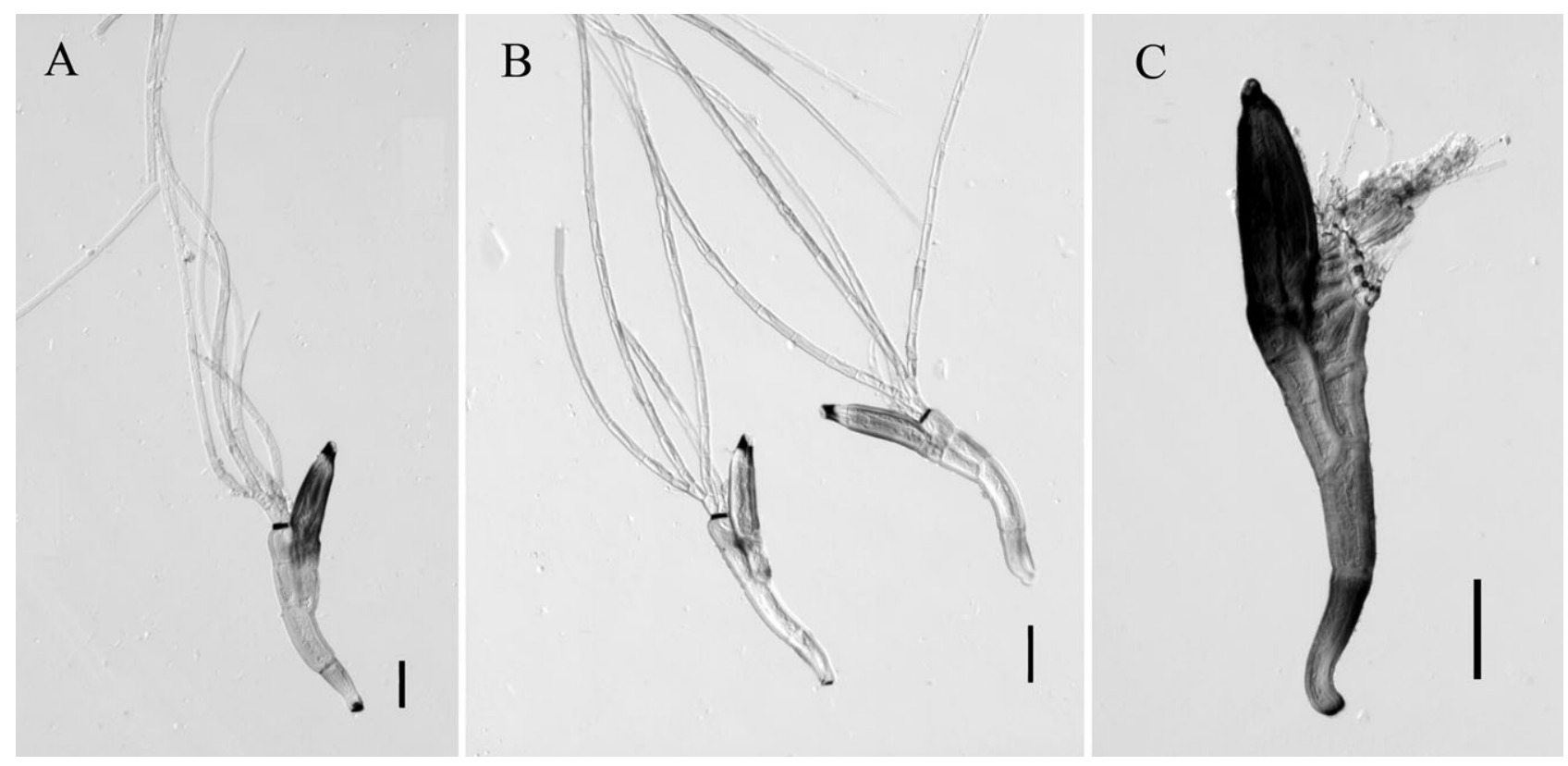

Fig. 2. Mature thalli of Laboulbenia species. A - L. coneglanensis; $\mathrm{B}-$ L. pseudomasei; $\mathrm{C}-$ L. fasciculata. $\mathrm{Bars:} \mathrm{A}=100 \mu \mathrm{m} ; \mathrm{B}=$ $50 \mu \mathrm{m} ; \mathrm{C}=100 \mu \mathrm{m}$.

Quercus (Fig. 1.; Yamazaki et al., 2002). The farmland site comprised a mosaic of coppice woodland, rice and vegetable fields, irrigation ponds and streams (Fig. 1.; Yamazaki et al., 2003). Based on the European Union Institute for Security Studies (EUNIS) Database (http://eunis.eea.europa.eu/index. jsp), the riverside site was categorized as "Species-rich helophyte beds"; the forest site as "Mixed woodland with [Cupressaceae], [Taxaceae] and evergreen oak"; and the farmland site as "Inundated or inundatable croplands, including rice fields". To examine the effect of microhabitat on the incidence of infection by laboulbenialean fungi, beetles were collected from 23 microhabitats in the three habitats; these included ten riverside microhabitats (Fig. 1; Table 1; riverbank, edge of track, tall reeds, kudzu vines, slope of a hollow, rotten wood, vine reeds, under stones, the shoulder of a terrace and marshy ground), five microhabitats in the secondary forest (Fig. 1; forest floor, small hollow in the forest, forest edge, side of a mountain path and rotten wood), and eight farmland microhabitats (Fig. 1; arable rice field, wet fallow rice field, dry fallow rice field, two types of fallow vegetable fields, fallow potato field, old fallow field, and bank of an irrigation pond). The microhabitats were categorized as in previous studies (Yamazaki et al., 1999, 2002, 2003; Table 1). Three quadrats $(1.6 \mathrm{~m} \times 1.6 \mathrm{~m})$ were established on the ground in each microhabitat except for collecting beetles from rotten wood and beneath stones. We then dug out each quadrat to a depth of $0.4 \mathrm{~m}$ using a hoe, inspected the soil and collected the beetles. To collect beetles overwintering in rotten wood, soft pieces of wood were selected (e.g., total volume of crushed wood, $0.32 \mathrm{~m}^{3}$ at the riverside) and any beetles inside the pieces of wood were collected. To collect beetles overwintering under stones at the riverside site, stones with lower surfaces buried to a depth of 10 to $20 \mathrm{~mm}(\mathrm{n}=43$ stones covering $3.17 \mathrm{~m}^{2}$ ) were selected, overturned, soil beneath them dug to a depth of $0.4 \mathrm{~m}$ and any beetles present collected.

The beetles were pinned and identified using a pictorial encyclopedia of the beetles of Japan (Uéno et al., 1985). The beetles were then examined under a stereomicroscope for the presence of laboulbenialean fungi. Thalli of Laboulbeniales on the surface of the body of a host are easily distinguished from those other fungi by their unique morphology (Tavares, 1985; Ben- jamin et al., 2004). The mature thalli of laboulbenialean fungi were removed using tweezers, mounted on glass slides in Berlese solution and identified (Benjamin et al., 2004). The species of Laboulbeniales was identified under an optical microscope using taxonomic literature (Sugiyama, 1973; Terada, 1996b, 1998; Rossi \& Weir, 1997). Host records of identified species are those cited in the literature (Sugiyama, 1973; Terada, 1996a, b, 1998; Rossi \& Weir, 1997; Santamaria, 1998). All specimens of Laboulbeniales collected in this study are deposited in the Forestry and Forest Products Research Institute at Tsukuba, Ibaraki Prefecture, Japan.

A generalized linear model (GLM) with binomial error distribution was used to determine the effects of host habitat on the incidence of infection by laboulbenialean fungi (JMP ver. 6.0; SAS Institute, Cary, NC). Host habitat (riverside, secondary forest or farmland) was the explanatory variable and whether or not $(1 / 0)$ each beetle was infected by these fungi the response variable. Similarly, a GLM was used to determine the effects of host microhabitat (explanatory variable) on the incidence of infection by laboulbenialean fungi (response variable) at the riverside site. However, as the species composition of host carabids differed among habitats (Yamazaki et al., 2004) this may have caused the differences in the incidence of infection at the three habitats. To avoid the effect that these differences in carabid species composition may have a GLM was used to compare the incidence of infection of the potential hosts (response variable) among habitats (explanatory variable). Potential hosts are those carabid species that are recorded as host species in previous reports. Although the incidence of infection at different times of the year may also vary it was not possible to determine what effect this may have on the incidence of infection in the three habitats because the data set was too small.

\section{RESULTS}

A total of 531 adults of 53 carabid species (nine subfamilies) were collected from three habitats (Table 2). The species composition of the carabids differed in the three habitats, with only two species occurring in all three habitats and 13 in two of the habitats (Table 2). An infec- 
TABLE 3. Infections by Laboulbenia fungi recorded in this study and in the literature.

\begin{tabular}{|c|c|c|c|c|}
\hline \multicolumn{2}{|r|}{ Host } & \multicolumn{3}{|c|}{ Numbers of individuals collected (number infected) } \\
\hline Subfamily & Species & L. coneglanensis & L.pseudomasei & L. fasciculate \\
\hline Pterostichinae & Pterostichus planicollis Motschulsky & $3(2)^{N R}$ & - & - \\
\hline Harpalinae & Harpalus eous Tschitscherine & $8(6) *$ T98 & - & - \\
\hline Harpalinae & Harpalus griseus (Panzer) & $3(1) * \mathrm{~T} 98$ & - & - \\
\hline Harpalinae & Harpalus niigatanus Schauberger & $2(1) * \mathrm{~T} 98$ & - & - \\
\hline Harpalinae & Harpalus sinicus Hope & $5(2) * \mathrm{~T} 98$ & - & - \\
\hline Harpalinae & Oxycentrus argutoroides (Bates) & - & $20(2)^{N R}$ & - \\
\hline Callistinae & Chlaenius inops Chaudoir & - & - & $3(2)^{*} \mathrm{~T} 96 \mathrm{a}$ \\
\hline Omophroninae & Omophron aequalis Morawitz & - & - & $0(0){ }^{* T 96 b}$ \\
\hline Patrobinae & Patrobus flavipes Motschulsky & - & - & $0(0)^{* \operatorname{Su} 73}$ \\
\hline Pterostichinae & Pterostichus anthracinum Illiger & - & $0(0) *$ RW98 & - \\
\hline Pterostichinae & Pterostichus cristatus Dufour & - & $0(0)^{* \mathrm{SA} 98}$ & - \\
\hline Pterostichinae & Pterostichus gracilis (Dejean) & - & $0(0)^{* \mathrm{SA} 98}$ & - \\
\hline Pterostichinae & Pterostichus luctuosus (Dejean) & - & $0(0)^{*} \mathrm{RW} 98$ & - \\
\hline Pterostichinae & Pterostichus micans Heer & - & $0(0)^{* \mathrm{RW} 98}$ & - \\
\hline Pterostichinae & Pterostichus minor (Gyllenhal) & - & $0(0) *$ RW98 & - \\
\hline Pterostichinae & Pterostichus nigrita (Fabricius) & - & $0(0)^{* \text { RW98 }}$ & - \\
\hline Pterostichinae & Pterostichus oenotrium (Ravizza) & - & $0(0) *$ RW98 & - \\
\hline Pterostichinae & Pterostichus orientalis Motsch. & - & $0(0)^{* \mathrm{RW} 98}$ & - \\
\hline Pterostichinae & Pterostichus rhaeticum (Heer) & - & $0(0)^{* \text { RW98 }}$ & - \\
\hline Harpalinae & Anisodactylus punctatipennis Morawitz & $1(0)^{*} \mathrm{~T} 98$ & - & - \\
\hline Harpalinae & Anisodactylus sadoensis Schauberger & $13(0)^{*} \mathrm{~T} 98$ & - & - \\
\hline Harpalinae & Harpalus capito Morawitz & $3(0) * \mathrm{~T} 98$ & - & - \\
\hline Harpalinae & Harpalus discrepans Morawitz & $0(0) * \mathrm{~T} 98$ & - & - \\
\hline Harpalinae & Harpalus jureceki (Jedlicka) & $6(0) * \mathrm{~T} 98$ & - & - \\
\hline Harpalinae & Harpalus platynotus Bates & $4(0) *$ T98 & - & - \\
\hline Harpalinae & Harpalus psedoophonoides Schauberger & $0(0) * \mathrm{~T} 98$ & - & - \\
\hline Harpalinae & Harpalus roninus Bates & $0(0)^{*}$ T98 & - & - \\
\hline Harpalinae & Harpalus simplicidens Schauberger & $0(0) *$ T98 & - & - \\
\hline Harpalinae & Harpalus tinctulus Bates & $1(0) *$ T98 & - & - \\
\hline Harpalinae & Harpalus tridens Morawitz & $4(0) * \mathrm{~T} 98$ & - & - \\
\hline Harpalinae & Harpalus vicarious Harold & $0(0)^{*} \mathrm{~T} 98$ & - & - \\
\hline Callistinae & Chlaenius prostenus Bates & - & - & $0(0)^{*} \mathrm{~T} 96 \mathrm{a}$ \\
\hline Callistinae & Chlaenius vestitus (Paykull) & - & - & $0(0)^{*}$ T96a \\
\hline
\end{tabular}

*Host records reported in previous studies; citation references, SU73 (Sugiyama, 1973), T96a (Terada, 1996a), T96b (Terada, 1996b), T98 (Terada, 1998), RW98 (Rossi \& Weir, 1998), SA98 (Santamaria, 1998); ${ }^{\mathrm{NR}}$, new host record; - Not recorded.

tion by laboulbenialean fungi of one, five and one species of the carabid subfamilies Pterostichinae, Harpalinae and Callistinae, respectively, were detected (Table 2). Three species of the genus Laboulbenia (Laboulbeniales) were identified: L. coneglanensis Spegazzini (Fig. 2A), L. pseudomasei Thaxt (Fig. 2B) and L. fasciculata Peyritsch (Fig. 2C). The thalli of L. coneglanensis (Fig. 2A) were present on the surface of the elytra of five species: Harpalus eous Tschitscherine, H. griseus (Panzer), H. niigatanus Schauberger, H. sinicus Hope and Pterostichus planicollis Motschulsky (Table 3). The thalli of L. pseudomasei (Fig. 2B) were present on the surface of the elytra and legs of Oxycentrus argutoroides (Bates) (Table 3 ) and those of L. fasciculata (Fig. 2C) on the surface of the elytra and prothorax of Chlaenius inops Chaudoir (Table 3). Although most of these host records are not new, two are first records (Table 3). Fourteen species were infected with either L. coneglanensis, L. pseudomasei or L. fasciculata (Table 3).

The incidence of infection by Laboulbenia differed among habitats (GLM, $d f=2, \chi^{2}=26.7, P<0.0001$ ); it was higher at the riverside site $(8.97 \%$ of individuals;
$14 / 156)$ than at the forest $(0.93 \% ; 2 / 214)$ and farmland sites $(0 \% ; 0 / 161$; Table 2$)$. The difference in the incidence of infection of the 14 potential hosts by three Laboulbenia species in the different habitats was marginally significant (GLM, $\left.d f=2, \chi^{2}=5.9, P=0.05\right)$; riverside, $23.7 \%(14 / 59)$, forest, $33.3 \%(2 / 6)$ and farmland, $0 \%(0 / 11)$.

At the riverside site, the incidence of infection by Laboulbenia ranged from 0 to $33.3 \%$ in the different microhabitats in which the carabid beetles overwintered (Table 4) and differed significantly among microhabitats (Table 4; GLM, $d f=9, \chi^{2}=20.6, P=0.0147$ ).

\section{DISCUSSION}

This report provides quantitative data on the incidence of infection by three species of laboulbenialean fungi of 53 species of carabid (Table 2). This study is the first to indicate a difference in the incidence of infection by these fungi at two different scales: habitat and microhabitat (Tables 2,4). As the incidence of infection by fungi is generally higher in humid environments, carabid beetles, which inhabit the wettest environment (riverside), should 
TABLE 4. The percentage incidence of infection of carabid beetles by Laboulbenia in the different microhabitats.

\begin{tabular}{cccc}
\hline Code* $^{*}$ & Microhabitat* & Total number of individuals collected & Number of infected individuals (\%) \\
\hline A & Riverbank & 5 & $0(0)$ \\
B & Edge of track & 18 & $6(33.3)$ \\
C & Tall reeds & 4 & $1(25.0)$ \\
D & Kudzu vines & 9 & $0(0)$ \\
E & Slope of a hollow & 11 & $1(9.1)$ \\
F & Rotten wood & 24 & $0(0)$ \\
G & Vine reeds & 28 & $2(7.1)$ \\
H & Under stones & 32 & $1(3.1)$ \\
I & Shoulder of a terrace & 18 & $3(16.7)$ \\
J & Marshy ground & 7 & $0(0)$ \\
\hline
\end{tabular}

*Microhabitats and their codes are described in Table 1 and illustrated in Fig. 1.

be subject to high incidences of infection by laboulbenialean fungi. The absence of infection by these fungi at the farmland site may be related to the drier conditions prevailing there. However, this difference in the incidence of infection may result from the difference in species composition of host carabids in the different habitats because laboulbenialean fungi are known to infect a particular host genus or species. For example, although $L$. coneglanensis is recorded from many Harpalus species (Table 3; Terada, 1998) no individuals of this genus were infected with this fungus at the farmland site (Table 3).

Factors other than host species are important determinants of the different incidences of infection in the different habitats. Andersen \& Skorping (1991) demonstrated experimentally that the differences in the incidence of infection by Laboulbenia fungi of assemblages of Bembidion beetles are associated with both microhabitat and host taxon. De Kesel (1996b) also suggests that the microhabitat of the host directly affects the growth and development of Laboulbenia thalli on the bodies of its hosts. Similarly, both the habitat and microhabitat may be important in determining the successful establishment of these fungi on the bodies of their hosts.

ACKNOWLEDGEMENTS. We thank K. Kawamura for help with the collecting of the carabid beetles, Y. Yamaura for statistical advice, B.S. Holland for helpful advice, and two anonymous reviewers for providing valuable comments on earlier drafts of this manuscript.

\section{REFERENCES}

ANDERsen J. \& Skorping A. 1991: Parasites of carabid beetles: prevalence depends on habitat selection of the host. Can. J. Zool. 69: 1216-1220.

Benjamin R.K., Blackwell M., Chapela I.H., Humber R.A., Jones K.G., Klepzig K.D., Lichtwardt R.W., Malloch D., Noda H., Roeper R.A., Spatafora J.W. \& Weir A. 2004: Insect- and other arthropod-associated fungi. In Mueller G.M., Bills G.F. \& Foster M.S. (eds): Biodiversity of Fungi: Inventory and Monitoring Methods. Elsevier, Burlington, MA, pp. 395-434.

De Kesel A. 1996a: Relative importance of direct and indirect infection in the transmission Laboulbenia slackensis (Ascomycietes, Laboulbeniales) form Pogonus chalceus (Coleoptera, Carabidae). Belg. J. Bot. 126: 155-163.

De Kesel A. 1996b: Host specificity and habitat preference of Laboulbenia slackensis. Mycologia 88: 565-573.
Harwood J.D., Ricci C., Romani R., Pitz K.M., Weir A. \& OBRYCKI J.J. 2006: Prevalence and association of the laboulbenialean fungus Hesperomyces virescens (Laboulbeniales: Laboulbeniaceae) on coccinellid hosts (Coleoptera: Coccinellidae) in Kentucky, USA. Eur. J. Entomol. 103: 799-804.

Löver G.L. \& SunderLAND K.D. 1996: Ecology and behavior of ground beetles (Coleoptera: Carabidae). Annu. Rev. Entomol. 41: 231-256.

Niemelä J., Kotze D.J., Venn S., Penev L., Stoyanov I., Spence J., Hartley D. \& de OcA E.M. 2002: Carabid beetle assemblages (Coleoptera, Carabidae) across urban-rural gradients: an international comparison. Landsc. Ecol. 17: 387-401.

Rainio J. \& Niemelä J. 2003: Ground beetles (Coleoptera: Carabidae) as bioindicators. Biodivers. Conserv. 12: 487-506.

RIDDICK E.W. 2006: Influence of host gender on infection rate, density and distribution of the parasitic fungus, Hesperomyces virescens, on the multicolored Asian lady beetle, Harmonia axyridis. J. Insect Sci. 98: 615-624.

Riddick E.W. \& Schaefer P.W. 2005: Occurrence, density, and distribution of parasitic fungus Hesperomyces virescens (Laboulbeniales: Laboulbeniaceae) on multicolored Asian lady beetle (Coleoptera: Coccinellidae). Ann. Entomol. Soc. Am. 98: 615-624.

Rossi W. \& WeIR A. 1997: Laboulbenia pterostichi and its allies. Mycol. Res. 101: 129-134.

Roy B.A. 1994: The use and abuse of pollinators by fungi. Trends Ecol. Evol. 9: 335-339.

Roy H.E. \& Cottrell T.E. 2008: Forgotten natural enemies: Interactions between coccinellids and insect-parasitic fungi. Eur. J. Entomol. 105: 391-398.

SANTAMARIA S. 1998: Laboulbeniales, I. Laboulbenia. Flora Mycol. Iberica 4: 1-186.

SugrYAmA K. 1973: Species and genera of the Loboulbeniales (Ascomycetes) in Japan. Ginkgoana 2: 1-97.

TAVARES I.I. 1985: Laboulbeniales (Fungi, Ascomycetes). Mycologia Memoir No. 9. J. Cramer, Braunschweig, 627 pp.

TERAda K. 1996a: New or interesting Laboulbeniales (Ascomycetes) on Japanese chlaeniine beetles (Coleoptera, Carabidae). Mycoscience 39: 425-431.

TERADA K. 1996b: Additional records on the Loboulbeniales (Ascomycetes) and their carabid hosts (Coleoptera, Carabidae). Trans. Mycol. Soc. Jap. 37: 155-165.

TERADA K. 1998: Notes on Laboulbenia coneglanensis (Ascomycetes, Laboulbeniales) in Japan. Mycoscience 39: 425-431.

Uéno S., Kurosawa Y. \& Satô M. (eds) 1985: The Coleoptera of Japan in Color Vol. II. Hoikusha, Osaka, 514 pp. 
Yamazaki K., Sugiura S. \& Kawamura K. 1999: Overwintering ground beetle assemblages along the Kizu River, Kyoto. Entomol. Sci. 2: 33-40.

YamazaKi K., Sugiura S. \& Kawamura K. 2002: Environmental factors affecting the overwintering distribution of ground beetles (Coleoptera: Carabidae) at a forest floor in central Japan. Entomol. Sci. 5: 125-130.

Yamazaki K., Sugiura S. \& Kawamura K. 2003: Ground beetles (Coleoptera: Carabidae) and other insect predators overwintering in arable and fallow fields in central Japan. Appl. Entomol. Zool. 38: 449-459.

YamazaKi K., Sugiura S. \& Kawamura K. 2004: Overwintering site selection in carabid beetles: from investigations at a river bank, forest floor and farmland (in Japanese). Nature Insects 39: 31-35.

Vega F.E. \& Blackwell M. 2005: Insect-Fungal Associations: Ecology and Evolution. Oxford University Press, New York, $352 \mathrm{pp}$.
Weir A. \& Hammond P.M. 1997a: A preliminary assessment of species-richness patters of tropical, beetle-associated Laboulbeniales (Ascomycetes). In Hyde K.D. (ed.): Biodiversity of Tropical Microfungi. Hong Kong University Press, Hong Kong, pp. 121-139.

Weir A. \& Hammond P.M. 1997b: Laboulbeniales on beetles: host utilization patterns and species richness of the parasites. Biodivers. Conserv. 6: 701-719.

Welch V.L., Sloggett J.J., Webberley K.M. \& Hurst G.D.D. 2001: Short-range clinal variation in the prevalence of a sexually transmitted fungus associated with urbanisation. Ecol. Entomol. 26: 547-550.

Zerm M. \& AdIS J. 2004: Seasonality of Laboulbenia phaeoxanthae (Ascomycota, Laboulbeniales) and its host Phaeoxantha aequinoctialis (Coleoptera, Carabidae) at a central Amazonian blackwater floodplain. Mycol. Res. 108: 590-594.

Received July 10, 2009; revised and accepted October 1, 2009 